\title{
Hinweis \\ auf den VII. Kongreß der IVG \\ (Ausschreibung des wissenschaftlichen Programms)
}

Unter dem Generalthema 'Kontroversen, alte und neue' soll der VII. Kongreß der Internationalen Vereinigung für Germanische Sprach- und Literaturwissenschaft vom 25.-31. August 1985 in Göttingen (Bundesrepublik Deutschland) stattfinden. Die Ausschreibung des wissenschaftlichen Programms wird den Mitgliedern der IVG zum Jahresende 1983 zugeschickt und kann von weiteren Interessenten angefordert werden beim

\section{IVG-Sekretariat. Nikolausberger Weg 15. D-3400 Göttingen.}

Vorgeschlagene Sektionen (Foren):

1. Verständlichkeit und wissenschaftlicher Anspruch: Kontroversen um die Sprache der Germanisten

2. Formen und Formengeschichte des Streitens

3. Textlinguistik contra Stilistik?

4. Wortschatz und Wörterbuch

5. Grammatische oder pragmatische Organisation von Rede?

6. Sprachnormen: lösbare und unlösbare Probleme

7. Kontroversen um die neuere deutsche Sprachgeschichte

8. Auseinandersetzungen um jiddische Sprache und Literatur

9. Dialektik und Soziolinguistik: Die Kontroverse um die Mundartforschung

10. Frauensprache-Frauenliteratur?

11. Bildungsexklusivität und Volkstümlichkeit

12. Ethische contra ästhetische Legitimation von Literatur

13. Der Literaturstreit

14. Traditionalismus und Modernismus: Kontroversen um den Avantgardismus

15. Literatur von Lessing: nur für Experten?

16. Deutsche Literatur in der Weltliteratur

17. Jüdische Komponenten in der deutschen Literatur - die Assimilationskontroverse

18. Kulturnation statt politischer Nation?

19. Vier deutsche Literaturen?

20. Literatur seit 1945: nur die alten Modelle?

21. Audiovisuelle Medien: das Ende der Literatur?

22. Historische und aktuelle Konzepte der Literaturgeschichtsschreibung

23. Für und Wider einer Psychoanalyse literarischer Werke

24. Kontroverse Exegesen

25. 'Schlegel oder Grimm?' Wissenschaftsgschichtliche Alternativen in der Germanistik von der Frühromantik bis zur Gegenwart

In der Ausschreibung werden diese Sektionen erläutert, Vorschläge für entsprechende Sektionsreferate (Exposés) bis zum 30. April 1984 erbeten und die Spielregeln mitgeteilt, die dafür gelten sollen.

Das aufgrund dieser Vorschläge der Beiträger zusammengestellte Vorprogramm (mit Angaben auch über die Plenarvorträge, kulturellen Veranstaltungen, Exkursionen, Ausstellungen etc.) soll den Mitgliedern der IVG im Herbst 1984 zugehen und kann dann von Nicht-Mitgliedern wiederum beim Göttinger Sekretariat angefordert werden - zusammen mit dem Formular der Teilnahme-Anmeldung und gegebenenfalls dem eines Antrags auf Mitgliedschaft in der IVG.

Prof. Dr. Albrecht Schöne (Präsident der IVG) 